\title{
POSTER
}

\section{Health and Self-Esteem}

S.M. FLYNN, V.Y. OVIEDO, W.N. HOFFMANN J. STEVENS-LAPSLEY, P. ROBERTS, S. BINI. Reliability, Validity and Usability of a digital education and self-assessment app for adults with knee osteoarthritis. Gerontechnology 2018;17(Suppl):158s-159s; https://doi.org/10.4017/gt.2018.17.s.154.00 Purpose According to the CDC, "Arthritis affects 52.5 million US adults - more than 1 of 5 . It is the leading cause of disability in the US and one of the most common chronic conditions in the nation." ${ }^{1}$ In 2003, direct medical costs + additional costs lost in earnings were estimated to exceed $\$ 128 \mathrm{~B} /$ year ${ }^{1}$. Total knee and total hip replacement (TKR/THR) are the treatments of choice for end-stage arthritis of the knee and hip. Today, more than $1 \mathrm{M}$ TKR/THR surgeries are performed in the US; this number is expected to balloon to more than $4 \mathrm{M}$ by $2030^{2}$. Preoperative total joint physical therapy (PT) and education classes reduce post-acute care utilization by more than $29 \%$ with a savings of $\$ 1215$ per person, yet approximately $50 \%$ of patients do not attend ${ }^{3}$. Considering there will be more than $4 \mathrm{M}$ TKR/THRs performed in the US soon, $100 \%$ participation in preoperative PT can save the US \$5B. The purpose of this study is to test The Oaks, a new software application (app) that will provide a solution for the delivery of perioperative education, assessment, and exercise for adults living with knee osteoarthritis $(\mathrm{KOA})$ and to directly impact healthcare systems in improving patient care and outcomes. Data captured from The Oaks could be used in future arthritis research. The first step in validating this app, is to complete a feasibility and usability study. Method The participants performed two rounds of the following activities: download the app, perform the Timed Up and Go (TUG) test and complete the education Lesson. Outcomes included comparison of Round 1 (R1) with Round 2 (R2) in terms of time to complete, requests for help, scores compared to standard care, and usability scores (using the System Usability Scale). Concurrent validity of the TUG test was compared using the app (SELF) and standard care measurement using a stopwatch (STANDARD). Results \& Discussion Eleven adults, $n=9$ female, aged $70.8(9.7 ; 59-86)$ with KOA participated in the study. Six of the participants had received a TKR, the others are either awaiting or considering TKR in the future. Time to Complete: Using t-tests we found that the R2 TUG was statistically significantly faster $(301.00$ secs; 41.60$)$ than R1 (379.55 secs; SD66.38), $p=.029$. Similarly, the Lesson R2 was statistically significantly faster (331.27 secs; SD52.70) than R1 (469.00 secs; SD124.83); $p=.004$. Requests for help: Using t-tests we found that participants requested help statistically less frequently during the TUG R2 (.55; SD1.03) than R1 (1.82; SD2.40); $p=.022$. Similarly, participants had statistically significantly fewer requests for help in the Lesson R2 (.55; SD.82) than R1 (1.55; SD1.75); $p=.041$. Scores: Using t-tests, we found that participants scored statistically significantly better in R2 in the Lesson (84.7\% correct; SD24.6\%), compared with R1 (54.8\% correct; SD31.6\%); $(p=.029)$. Concurrent Validity: Correlations (Pearson's correlations ( $r)$ ) between STANDARD and SELF were excellent and statistically significant at $\mathrm{p}<0.01$ (Table 1). Usability: The SUS scores were calculated based on standardized methods to identify the percentile rank of the product's usability and learnability. The SUS was completed using standard practice (paper questionnaire). Participants scored the TUG as $75.45^{\text {tho }}$ ile (SD15.24) in R1

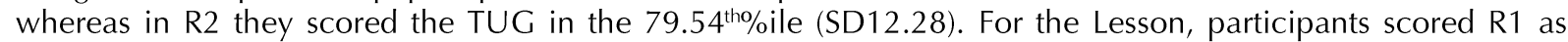
$70.45^{\text {tho }}$ ile (SD18.09) and R2 as 78.40\% $\%$ ile (SD24.14). In conclusion, participants completed the tasks faster and with fewer questions during R2, indicating that the app was usable and easy to learn. Participants were accurate in their self-assessment of the TUG test indicating that older adults can be taught how to perform standardized self-assessments on their own using digital tools. Participants improved their scores on the Lesson in R2. These findings offer preliminary evidence that the content presented in preoperative education classes may require more time and repetition for older adults to learn. The Oaks app provides an opportunity for older adults to rehearse this material as often as they wish prior to surgery and self-assess their function. In conclusion, The Oaks app shows promise in offering adults with KOA preoperative educational material as an alternative to attending a hospital-based class, which could improve knowledge and lower healthcare costs.

\section{References}

1. Centers for Disease Control and Prevention. Arthritis. in Arthritis, Vol. 2016 [ed. Centers for Disease Control and Prevention]. usa.gov, Atlanta Ga, 2016

2. Centers for Disease Control and Prevention. Inpatient Surgery. in National Center for Health Statistics, Vol. 2016 [ed. Centers for Disease Control and Prevention]. Atlanta Ga, 2015

3. Snow R, Granata J, Ruhil AV, Vogel K, McShane M, Wasielewski R. Associations between preoperative physical therapy and post-acute care utilization patterns and cost in total joint replacement. J Bone Joint Surg Am. 2014 Oct 1; 96(19):e165 


\section{POSTER}

\section{Health and Self-Esteem}

Keywords: arthritis, education, telemedicine, total knee replacement, rehabilitation Address: Blue Marble Health 2400 Lincoln Ave, Altadena CA 91001;

E: sheryl@bluemarblehealthco.com

\begin{tabular}{|c|c|c|}
\hline Variable & $\begin{array}{c}\text { Round 1 } \\
\text { (Standard v Self) }\end{array}$ & $\begin{array}{c}\text { Round 2 } \\
\text { (Standard v Self) }\end{array}$ \\
\hline Practice & $.916^{\star *}$ & $.981^{\star *}$ \\
Trial 1 & $.979^{\star *}$ & $.994^{\star *}$ \\
Trial 2 & $.983^{\star *}$ & $.957^{\star *}$ \\
\hline \multicolumn{3}{|c}{ Table 1. Concurrent Validity }
\end{tabular}

